\title{
Exame Nacional do Ensino Médio (ENEM): Conteúdo matemático mais abordado e suas dificuldades
}

\author{
National High School Exam (ENEM): Mathematical content more addressed and its difficulties \\ Examen Nacional de Bachillerato (ENEM): Contenido matemático más abordado y sus dificultades
}

Recebido: 13/05/2021 | Revisado: 19/05/2021 | Aceito: 23/05/2021 | Publicado: 08/06/2021

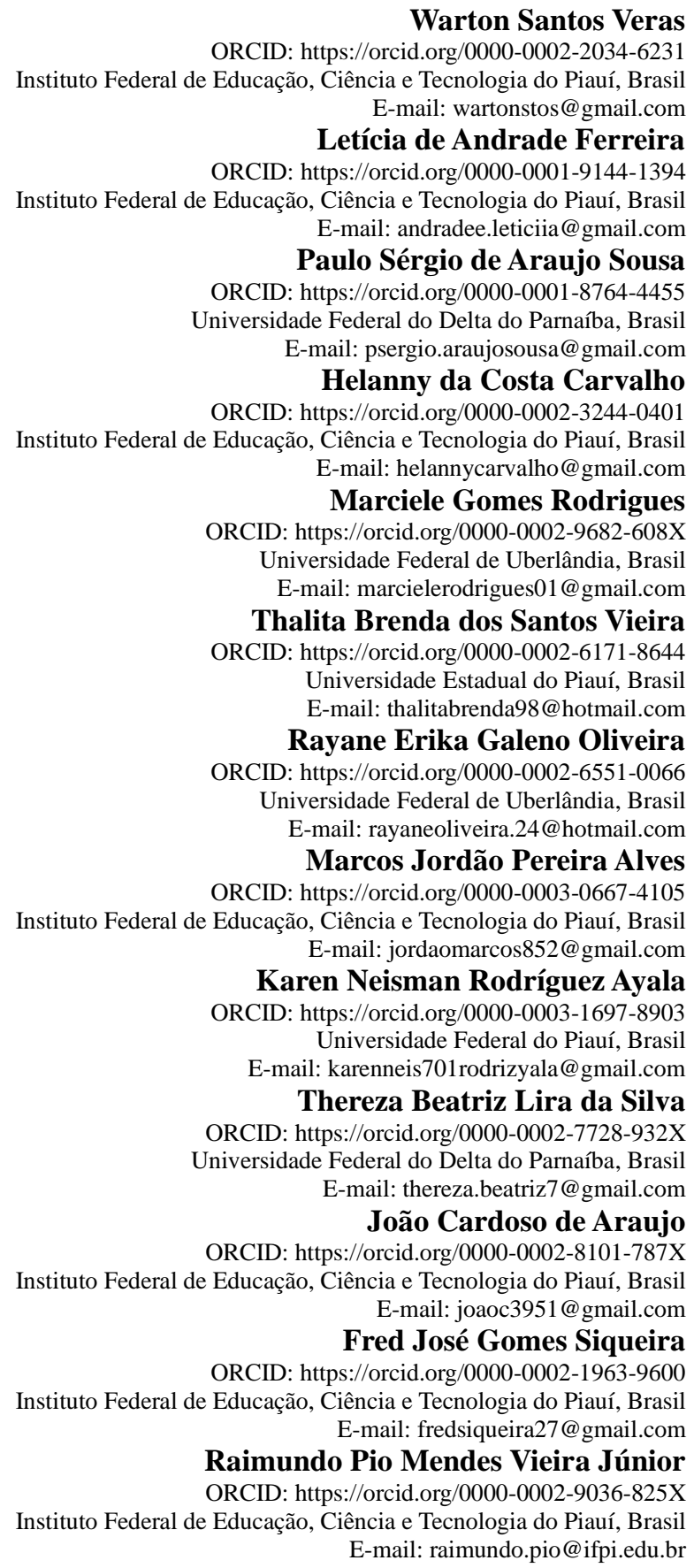

\section{Resumo}

O Exame Nacional do Ensino Médio (ENEM), tornou-se um dos principais meios de ingresso ao ensino superior, visto que a Matemática tem uma influência importante na média final, sendo que a mesma é elaborada de acordo com os conteúdos que devem ser abordados durante toda a educação básica. Neste sentido, o estudo teve como objetivo 
analisar e descrever qual o conteúdo mais abordado, quais as dificuldades que os alunos enfrentam ao se depararem com essas questões de Matemática presente nas provas do ENEM, com isso propor estratégias para minimizar essas dificuldades. Este é um estudo descritivo, exploratório e aplicado, em que, inicialmente, foram analisadas as provas de 2012 a 2018 do ENEM, no qual quantificou-se as questões atribuindo-se seus respectivos conteúdo. Em seguida, realizou-se a aplicação de questionários (pré-teste) para os discentes, o mesmo possuía 7 questões. Posteriormente realizou-se uma intervenção sobre o assunto mais abordado no ENEM, após essa intervenção foi aplicado um pósteste com o total de 8 questões. Analisando as provas, constatou-se que o conteúdo mais abordado foi o de estatística, no qual foram quantificadas 70 questões. Com o pré-teste os discentes atribuíram o conceito sobre estatística de forma correta, entretanto não conseguiram interpretar a maioria das questões. Após a intervenção e com a realização do pósteste os alunos apresentaram melhor resultado, fato este que foi comprovado pelo desempenho nas resoluções das questões. Através do estudo, conclui-se que os alunos possuem dificuldades, assim como a interpretação e compreensão de gráficos e tabelas.

Palavras-chave: Exame nacional do ensino médio; Questionários; Alunos.

\begin{abstract}
The National High School Exam (ENEM) has become one of the main means of entry to higher education. Mathematics has an influence on the final average, and it is elaborated according to the contents that must be addressed throughout basic education. In this sense, the study aimed to analyze and describe which content is most addressed, what are the difficulties students face when faced with these Mathematics issues present in the ENEM tests, thus proposing strategies to minimize these difficulties. This is a descriptive, exploratory and applied study, in which, initially the exams from 2012 to 2018 of ENEM were analyzed, in which the questions were quantified by attributing their respective contents. Then, questionnaires (pretest) were applied to students in the 3rd year classes of the Federal Institute of Piauí (IFPI) Cocal campus and the Deputado Pinheiro Machado High School, which had 7 questions. Subsequently, an intervention was held on the subject most addressed in ENEM. After this intervention was applied post-test with a total of 8 questions. Analyzing the evidence, it was found that the most addressed content was statistics, in which 70 questions were quantified. With the pretest, students attributed the concept of statistics correctly but failed to interpret most of the questions. After the intervention and after the post-test students performed better, the fact that has been proven by performance in the resolutions of the issues. Through the study, it is concluded that the students have difficulties, as well as the interpretation and understanding of graphs and tables.
\end{abstract}

Keywords: National high school exam; Questionnaires; Students.

\title{
Resumen
}

El Examen Nacional de Bachillerato (ENEM), se ha convertido en uno de los principales medios para ingresar al nivel de educación superior, siendo que las Matemáticas tienen una influencia importante en el promedio final, y se elaboran de acuerdo a los contenidos que se deben abordar a lo largo de la educación básica. En este sentido, el presente estudio tuvo como objetivo analizar y describir qué contenido es más abordado, qué dificultades afrontan los estudiantes al encontrar tales preguntas Matemáticas presentes en las pruebas ENEM, proponiendo así estrategias para minimizar estas dificultades. Se trata de un estudio descriptivo, exploratorio y aplicado, en el que, inicialmente se analizaron las pruebas ENEM de 2012 a 2018, cuantificando las preguntas y asignándoles su respectivo contenido. Luego, se aplicaron cuestionarios (pre-test) a los estudiantes, los cuales tenían 7 preguntas. Posteriormente, se realizó una intervención sobre el tema más abordado en ENEM, luego de esa intervención se aplicó un post-test con un total de 8 preguntas. Analizando la evidencia, se encontró que el contenido más abordado fue el estadístico, en el que se cuantificaron 70 preguntas. Con la prueba previa, los estudiantes atribuyeron correctamente el concepto de estadística, sin embargo, no pudieron interpretar la mayoría de las preguntas. Luego de la intervención y con la realización del post-test, los estudiantes presentaron un mejor resultado, hecho que quedó comprobado por su desempeño en la resolución de las preguntas. A través del estudio, se concluye que los estudiantes tienen dificultades, así como la interpretación y comprensión de gráficos y tablas.

Palabras clave: Examen nacional de bachillerato; Cuestionarios; Estudiantes.

\section{Introdução}

O processo de ensino e aprendizagem no Brasil passou por diversas mudanças nos últimos anos, muitas delas relacionadas ao acesso dos discentes no ingresso para o ensino superior. Uma das formas pela qual ocorre essa admissão se dá por meio do Exame Nacional do Ensino Médio (ENEM) (Andrade et al., 2020; Oliveira et al., 2020; Faria, Duque, 2021).

Anteriormente, o referido exame era utilizado apenas para analisar o processo de ensino-aprendizagem do ensino médio, mas atualmente é por meio deste que milhares de jovens têm acesso ao ensino superior em instituições públicas e privadas de ensino no país, inscrevendo-se no Sistema de Seleção Unificada (SISU) (Lima; Malange; Borges, 2018; Vargas, 2019; Soares; Soares; Santos, 2021), ou pelo Programa Universidade para Todos (ProUni) (Amaral; Oliveira, 2011; Hachem; 
Kalil, 2016; Costa; Ferreira, 2017; Felicetti, Cabrera, 2017), em que os estudantes podem ganhar bolsas em universidades particulares e também podendo usar sua nota no Financiamento Estudantil (FIES) (Costa, 2014; Almeida, 2015; Moreira, 2015; Vasconcelos, 2017; Miranda; Azevedo, 2020).

No ambiente científico, pesquisas já apontam que grande parte dos alunos que realizam o ENEM possuem grandes dificuldades na compreensão e resolução de questões relacionadas aos conteúdos mais abordados na prova de matemática (Arantes; Seabra, 2016; Piton-Gonçalves; Almeida, 2018; Pontes; Núñez, 2019). Assim, estudos relacionam que as dificuldades na resolução da prova estão relacionadas à contextualização das questões ou ao não conhecimento do conteúdo abordado, pois sabe-se que as mesmas são elaboradas de acordo com os conteúdos que deveriam ser trabalhados nas três séries do ensino médio (Reis, 2012; Carvalho, 2017; Reis; Nehring, 2017; Fidelis; Geglio, 2019). Além disso, pode-se admitir também que essa dificuldade seja resultante de uma base educacional não consolidada (Silva et al., 2018).

No que diz respeito à Matemática no ensino médio, pode se mencionar que na maioria das vezes, o tempo atribuído para a execução da disciplina não é o suficiente, pois os conteúdos são repassados de uma maneira superficial, tornando-se evidente que, ao final dos três anos do ensino médio os alunos não terão estudado e compreendido todos os conteúdos necessários para a realização da prova do ENEM, afetando o rendimento dos discentes na nota obtida na prova (Anjos; Moretti, 2017; Nakayama; Silva, 2017).

Para Silva (2014), a maioria dos alunos considera a disciplina de Matemática complexa e alegam que a mesma é difícil de compreender, tendo em vista que é necessário aprender diversos conteúdos desde as séries iniciais. Desta forma, é necessário perceber quais são as dificuldades enfrentadas por esses alunos no que diz respeito a resoluções de possíveis questões presentes em provas como a do ENEM, afinal, a nota atribuída à área do conhecimento de Matemática terá grande importância na composição da nota final do exame e, sendo assim, a mesma representará um ponto considerável quando se trata da continuidade da vida acadêmica.

Desse modo, o objetivo deste artigo é analisar e descrever os conteúdos mais abordados e as dificuldades que os alunos enfrentam ao se depararem com essas questões de Matemática presente nas provas do ENEM, propondo estratégias para minimizar essas dificuldades.

\section{Metodologia}

A pesquisa foi realizada no município de Cocal-PI, que possui população de 27.725 habitantes segundo IBGE (2018). Executou-se a pesquisa com os discentes da escola de Ensino Médio Deputado Pinheiro Machado (com 1254 alunos matriculados) e do Instituto Federal de Educação, Ciência e Tecnologia do Piauí (IFPI) campus Cocal (com 323 alunos matriculados no Ensino Médio), as duas turmas de $3^{\circ}$ ano foram escolhidas ao acaso, cada turma possuía 21 alunos. A pesquisa, com efeito, caracteriza-se como estudo descritivo, exploratório e aplicado, com fins explicativos e processo de análise quali-quantitavo. A geração de dados acontece por meio de documentação direta, obtida através de questionários, em fontes primárias e secundárias. O método de interpretação das informações é quantitativo, baseado nas respostas dos alunos nos questionários.

Inicialmente foi realizada uma pesquisa no Banco de Dados do INEP, órgão responsável pelo ENEM, para a obtenção dos arquivos das provas de Matemática e suas Tecnologias, assim como os seus respectivos gabaritos. Após isso, foram analisadas cerca de 7 provas, cada uma com 45 questões, totalizando 315, sendo que as mesmas foram separadas por conteúdos Matemáticos necessários para sua resolução. A análise abrangeu as provas de Matemática e suas tecnologias dos anos de 2012 a 2018, tendo como objetivo identificar o conteúdo Matemático mais cobrado. Após a análise dos dados, as questões foram separadas de acordo com seus conteúdos, assim foi possível elaborar uma avaliação diagnóstica montada de acordo com o conteúdo mais presente nos exames analisados. 
A primeira avaliação diagnóstica foi composta de um total de 7 questões, sendo que dentre estas, 4 questões eram objetivas e contavam com 4 opções de resposta sobre como o professor trabalha essas questões em sala de aula e 3 questões foram retiradas das provas analisadas sobre o assunto mais abordado, com 5 opções de resposta cada uma destas. O questionário contava com campos para o preenchimento de informações pessoais do aluno como: gênero, idade, série/turma e, logo abaixo, encontravam-se às questões. Essa avaliação foi aplicada em duas turmas de $3^{\circ}$ ano do ensino médio, uma na Escola de Ensino Médio Deputado Pinheiro Machado, e outra no IFPI campus Cocal, com isso foi analisado como os professores dessas turmas estão trabalhando com questões do ENEM, sendo possível assim estabelecer uma metodologia adequada para intervir, já que foi possível identificar as dificuldades que os alunos possuem através dessa avaliação diagnóstica.

Após a obtenção dos resultados da avaliação diagnóstica, foi proposto uma intervenção que consistia em uma aula detalhada sobre o conteúdo mais abordado no ENEM, relembrando seus principais conceitos e definições com auxílio de questões retiradas das provas analisadas e também com dicas importantes para a resolução durante a prova, isso para que os discentes conseguissem compreender como esse assunto é designado nas provas.

Após o final da intervenção foi aplicado uma nova avaliação, sendo desta vez composta por 8 questões objetivas do assunto mais cobrado com 5 opções de resposta cada, sendo as mesmas retiradas das provas analisadas. Ao final, foi realizada uma comparação dos resultados antes e pós-intervenção, em que foi possível analisar se a metodologia utilizada é realmente eficaz, quais as dificuldades minimizadas e as que não foram possíveis atenuarem.

\section{Resultados e Discussão}

\subsection{Análises dos conteúdos e das provas de matemática do ENEM}

O ENEM foi criado através das mudanças proporcionadas pela Lei de Diretrizes e Bases da Educação Nacional (LBD). Utilizando também como referências, os Parâmetros Curriculares Nacionais, as Diretrizes do Conselho Nacional de Educação referente à Educação Básica e os textos da reforma do Ensino Médio (Brasil,1996). Com isso, em maio de 1998 o Ministério de Educação e Cultura (MEC) criou o ENEM, com o objetivo de avaliar e tentar melhorar o rendimento no ensino médio, esse processo se perdurou até o ano de 2008 (Brasil, 1998).

A dificuldade em matemática por parte dos alunos, na prova do ENEM, se dá por vários motivos, e um deles pode ser a metodologia utilizada pelo próprio professor, que muitas vezes, torna o conteúdo abstrato, provocando assim, uma visão de que a Matemática é algo complexo de se aprender (Santos; França; Santos, 2007).

Outro fator que pode ser atribuído a essa dificuldade, é a não interpretação correta de enunciados de questões, pois para resolver atividades de Matemática é necessário se ter conhecimento dos conteúdos específicos e também entender o que a questão exige (Ribeiro; Mendes, 2016). Esses fatores negativos atribuídos à disciplina por parte do educando tem por consequência o sentimento de fracasso que prejudica o processo de ensino e aprendizagem da matemática (Santos; França; Santos, 2007).

Geralmente, para conseguir solucionar uma questão de matemática é necessário que os alunos tenham noções de vários conteúdos, pois sabe-se que a mesma é uma combinação de várias abordagens, nesse sentido buscou-se identificar através da análise das provas os principais conteúdos matemáticos necessário para resolução dos quesitos (Figura 1). 
Figura 1 - Análise das Provas do ENEM.

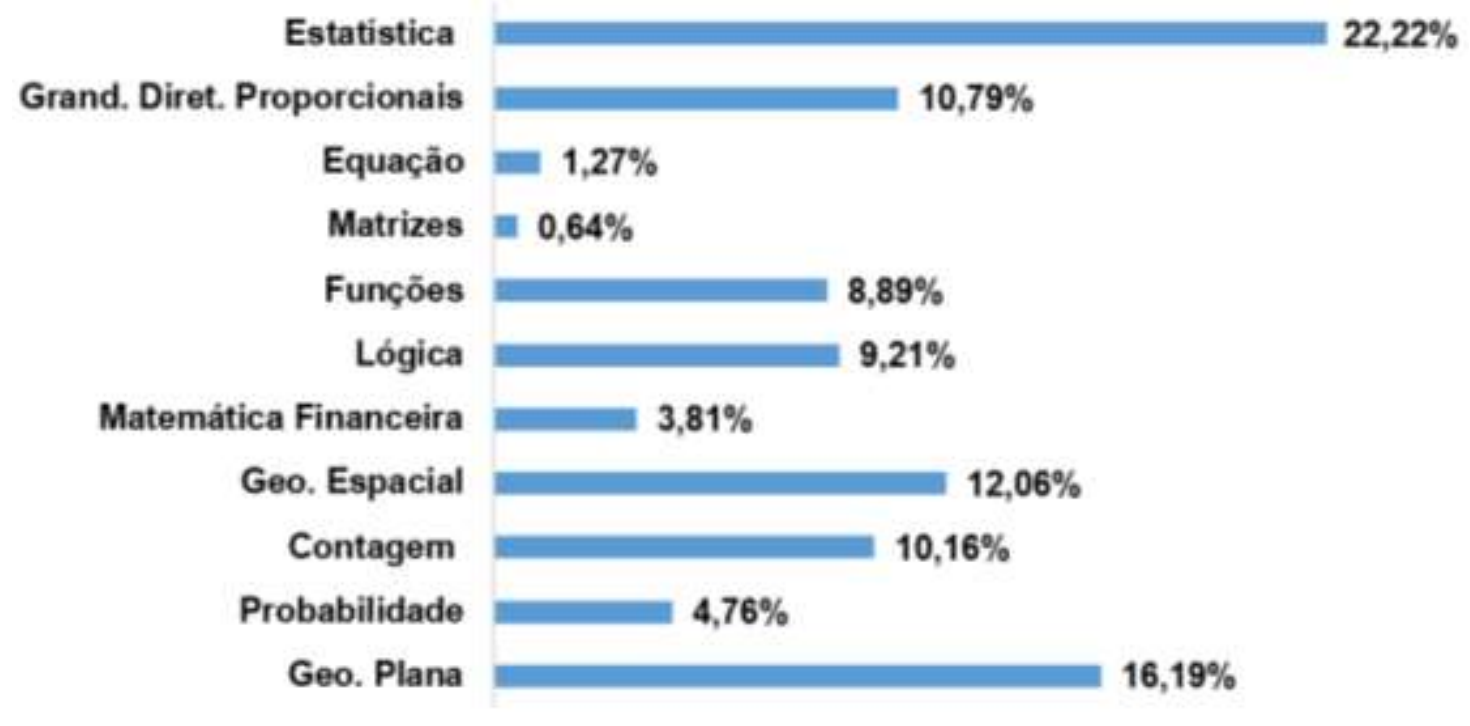

Fonte: Autores (2021).

Após a análise dos resultados obtidos, pôde-se observar a distribuição das 315 questões em 14 conteúdos, entre eles, o conteúdo sobre Estatística representa $22,22 \%$ das questões, ao todo são 70 questões, sendo que em média tem-se 10 questões por prova. De acordo com Albuquerque, Cordeiro e Silva (2013) o conteúdo sobre estatística têm-se encontrado nas provas do ENEM em grande quantidade, entretanto o mesmo não aparece com a mesma frequência nos livros didáticos.

Visto que que o conteúdo de Estatística é o mais cobrado no ENEM, é importante que os alunos tenham conhecimentos sobre o assunto, para que através destes possam compreender e solucionar questões propostas no exame. Ainda com relação aos conhecimentos sobre a Estatística, os Parâmetros Curriculares Nacionais - PCN (Brasil, 2000) defendem que o aluno tenha acesso a informações, e que isso seja proporcionado através do uso da contextualização, para que dessa forma os discentes possam reconhecer e propor soluções sobre a realidade na qual estejam inseridos.

\subsection{Aplicação dos questionários com os públicos-alvos das escolas Ensino Médio Deputado Pinheiro Machado e IFPI campus Cocal}

Após a análise das provas ser concluídas, realizou-se a aplicação do primeiro questionário. Nos campos destinados à obtenção de informações como idade e gênero, identificou-se que na escola de Ensino Médio Deputado Pinheiro Machado, $61,90 \%$ dos discentes são do gênero feminino e 38,10\% do sexo masculino, enquanto que no IFPI campus Cocal, 52,38\% dos alunos são do sexo feminino e 47,62\% masculino.

Após a aplicação desse primeiro questionário, foi realizada uma análise detalhada por questão e por turma, assim a primeira questão está relacionada aos conhecimentos dos estudantes com relação à definição de Estatística, com 4 opções de resposta, em que as quantidades de erros e acertos para as respostas dos alunos sobre este conceito está ilustrada na Figura 2. 
Figura 2 - Questão 1: De acordo com os seus conhecimentos, qual a definição de Estatística?

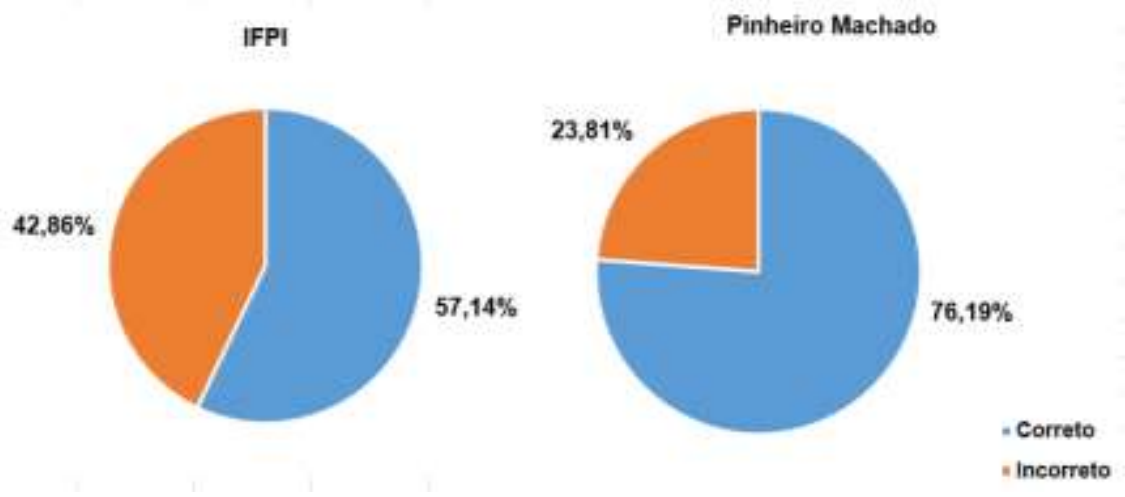

Fonte: Autores (2021).

Com base nestes resultados, pode-se perceber que na turma da escola Pinheiro Machado, cerca de 76,19\% dos alunos sabem a definição de Estatística. Já no IFPI é possível constatar que 42,86\% da turma não souberam definir o conceito de Estatística, sendo que é fundamental entender a definição para o desenvolvimento do aluno na disciplina (Lopes, 2008; Lopes, 2013; Silva; Curi; Schimiguel, 2017; Giordano; Araújo; Coutinho, 2019).

A segunda questão está relacionada sobre a forma como acontece a abordagem do conteúdo de Estatística, no qual os alunos tiveram 3 opções de respostas, podendo optar por afirmar que a aula é expositiva e dialogada com questões abstratas, expositiva e dialogada com questões contextualizadas e expositiva sem questões, respectivamente (Figura 3).

Figura 3 - Questão 2: A abordagem do conteúdo de Estatística ocorre de que maneira.

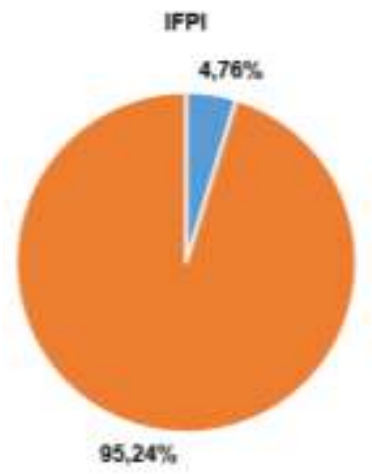

$95,24 \%$

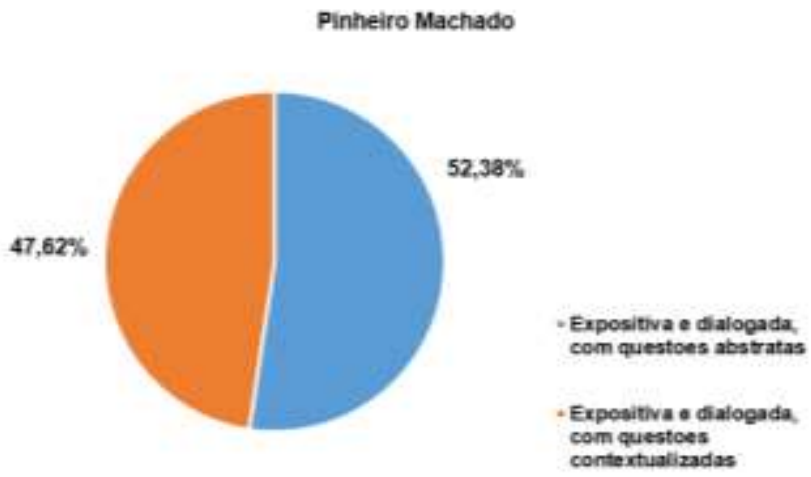

Fonte: Autores (2021).

Ao analisar os resultados, notou-se que a alternativa expositiva sem questões não foi mencionada, desta forma, constatou-se que os docentes se utilizam de questões durante a explanação dos conteúdos. Com relação a essas questões podese analisar que no IFPI os alunos quase que em sua totalidade, cerca de 95,24\% afirmaram que o professor utiliza questões contextualizadas ao abordar o assunto, enquanto que no Pinheiro Machado, 52,38\% dos discentes asseguraram que são utilizadas questões abstratas em suas aulas.

Percebeu-se que a contextualização é sempre utilizada pelos docentes e isso se torna um ponto positivo no ensino de matemática, devido a este procedimento potencializar o processo de ensino-aprendizagem dos alunos, facilitando a compreensão de conceitos e abrangendo as aplicações da matemática para exemplos do cotidiano que podem envolver outras áreas da ciência (Reis; Nehring, 2017; Santos et al., 2020; Santos, 2021; Santos et al., 2021). 
A terceira questão, que continha 4 opções de respostas, buscava identificar, por meio dos alunos, quais eram os tipos de questões utilizadas pelo professor. As alternativas para esta questões eram, respectivamente, questões de vestibular, questões do ENEM ou se o professor não trabalha esse tipo de questão (Figura 4).

Figura 4 - Questão 3: Durante a explicação do conteúdo de Estatística, quais as questões que são abordadas pelo professor.

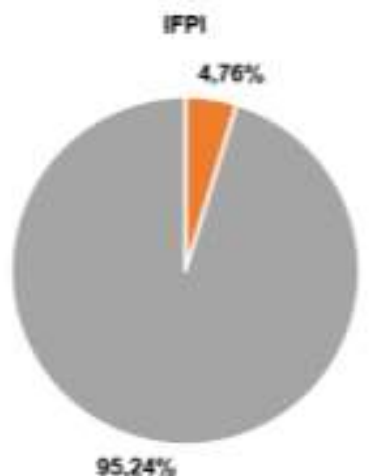

$95,24 \%$

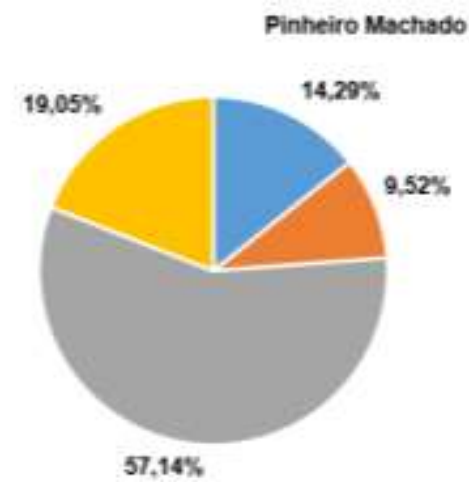

Fonte: Autores (2021).

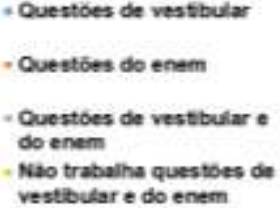

vestibular e do enem

Após quantificar todos esses resultados notou-se que na turma do IFPI, 95,24\% dos alunos afirmam que os professores utilizam questões do ENEM e de outros vestibulares. No Pinheiro Machado, percebeu-se que cerca de 57,14\% dos alunos também confirmaram que os docentes utilizam questões do ENEM e de outros vestibulares.

Com suporte na quarta questão, os estudantes foram indagados sobre a utilização dos conhecimentos de Estatística no seu cotidiano, na qual tiveram 4 opções de resposta, entre: totalmente, parcialmente, aleatoriamente e nunca. Os resultados desta questão seguem representados abaixo, na Figura 5.

Figura 5 - Questão 4: Com relação aos conhecimentos de Estatística, o mesmo é utilizado no seu cotidiano?

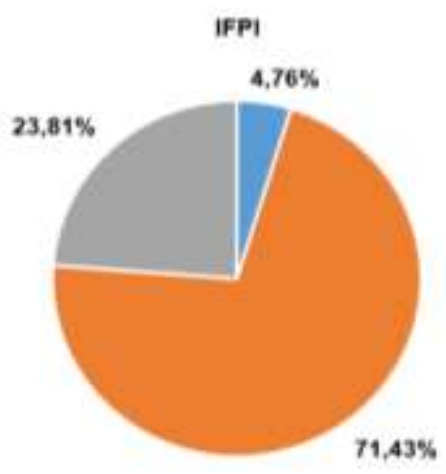

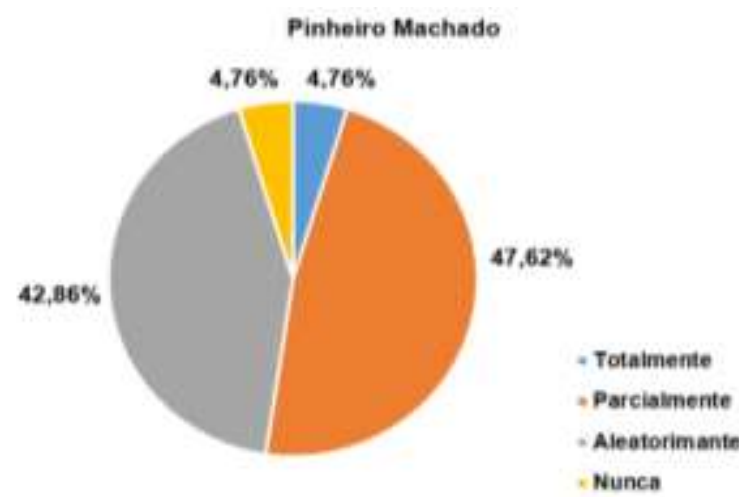

Fonte: Autores (2021).

A partir da análise (Figura 5), onde os discentes do IFPI tiveram como resposta 3 das 4 opções, sendo que 71,43\% dos alunos responderam que utilizam a Estatística no cotidiano de forma parcial, isto é, eles utilizam esses conhecimentos parcialmente, desses alunos apenas 4,76\% afirmam utilizar a estatística sempre. Na turma do Pinheiro Machado, os estudantes optaram pelas 4 opções de resposta, sendo que 47,62\% afirmaram usar esses conhecimentos de forma parcial e cerca de $42,86 \%$ usam de forma aleatória. 
De fato, a utilização do conteúdo de estatística no cotidiano dos discentes é importante para seu relacionamento no meio em que vivem, pois a mesma está presente na sociedade e é utilizado para facilitar a transferência de informações através de gráficos e tabelas (Leitão, 2011; Araújo, 2021; Silva; Santos, 2021).

A quinta questão foi retirada das provas que foram analisadas, a mesma possui 5 opções de resposta, na qual o aluno teria que calcular a Média Aritmética de acordo com as informações do enunciado, sendo esse um dos tópicos importantes dentro do conteúdo de Estatística. Um ponto importante que influência na resolução correta da questão é a interpretação da mesma. Desse modo, as respostas para esta questão encontram-se ilustradas na Figura 6.

Figura 6 - Questão 5: A mesma foi retirada da prova do Enem de 2014.
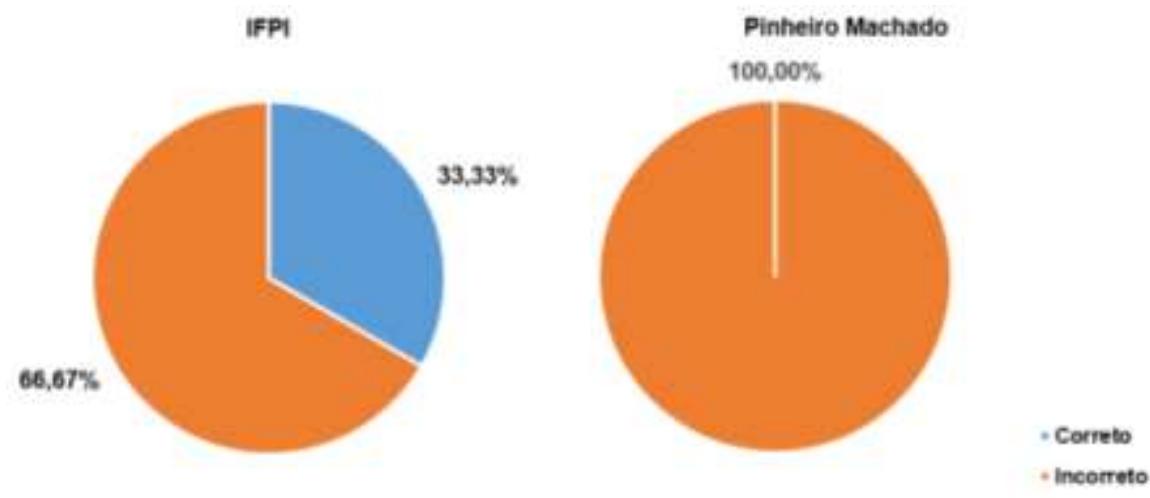

Fonte: Autores (2021).

Ao analisar o gráfico, observa-se que em ambas as turmas a maioria dos alunos responderam a questão de forma incorreta. Na turma do IFPI, cerca de 33,33\% dos discentes responderam corretamente à questão, mas quando analisado a turma do Pinheiro Machado, constata-se que exatamente todos os alunos erraram a questão. Além disso, foi possível constatar que durante a aplicação os alunos estavam tendo dificuldades em conceitos básicos de Média Aritmética e também na interpretação do enunciado da questão.

A sexta questão também foi retirada de provas do ENEM, a mesma está relacionada novamente a Média Aritmética, com interpretação de gráfico, onde seria necessário calcular a média das informações contidas no gráfico e comparar com uma média colocada pelo enunciado da questão (Figura 7).

Figura 7 - Questão 6: Retirada do Enem de 2013.
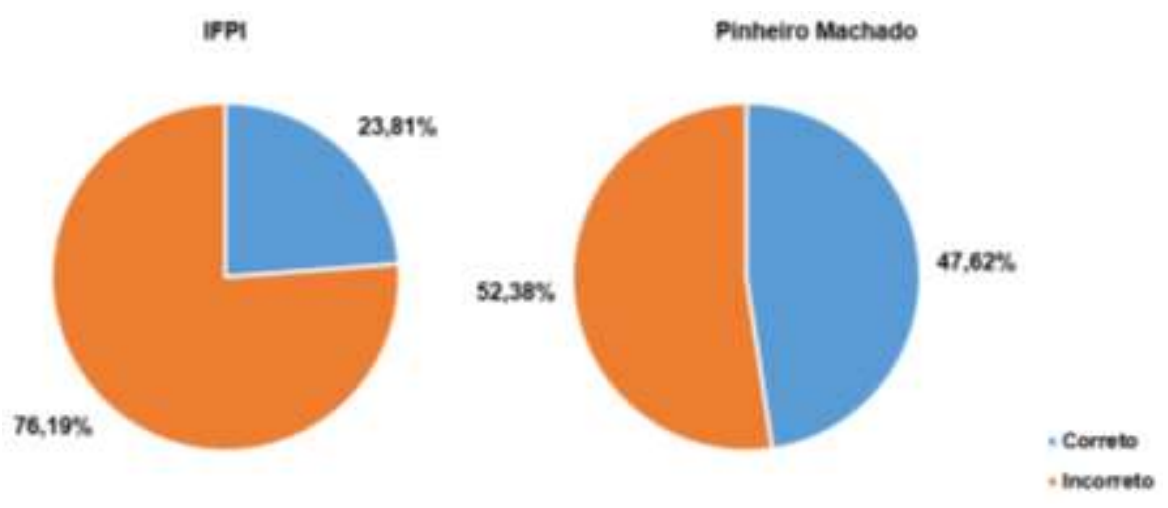

Fonte: Autores (2021). 
Fundamentado nos resultados exposto no gráfico, pode-se observar novamente que a maioria dos alunos das duas turmas não responderam corretamente à questão, sendo que cerca de 76,19\% dos alunos do IFPI erraram, já no Pinheiro Machado 52,38\% dos alunos responderam incorretamente.

Para finalizar o primeiro questionário, foi utilizado mais uma questão do ENEM, tendo como assunto a mediana, um tópico importante dentro da Estatística. A questão contava com a análise de um gráfico (Figura 8).

Figura 8 - Questão 7: Retirada da prova do Enem 2012.
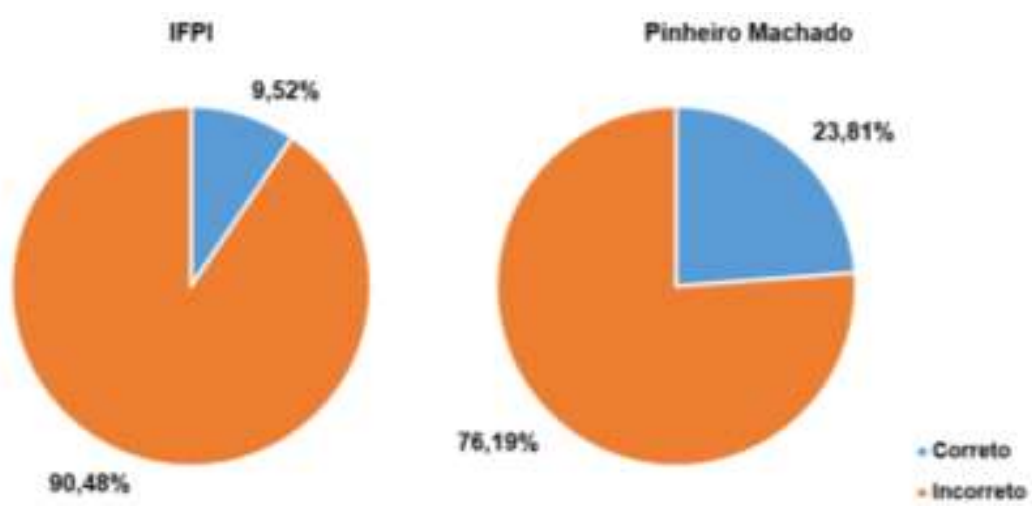

Fonte: Autores (2021).

Ao analisar o resultado dessa questão, percebeu-se que os alunos do IFPI possuem dificuldades em assuntos fundamentais de Estatística, no que se refere a conceitos básicos de mediana, pois apenas 9,52\% conseguiram responder a questão corretamente. Com relação à mesma questão, os alunos do Pinheiro Machado apresentaram apenas 23,81\% de êxito ao responder à questão, porém mesmo tendo um nível de acerto maior em comparação a turma do IFPI, constatou-se que esses estudantes também possuem dificuldades ao referido assunto.

Ao analisar os resultados obtidos nas Figuras 6, 7 e 8, notou-se que os discentes apresentaram dificuldades, tanto no conteúdo, como na interpretação do enunciado das questões. Desta forma, é notório a necessidade de criar meios que possibilitem aos alunos o desenvolvimento de habilidades, para que estes possam ter um melhor rendimento quando forem solucionar questões que abordem o assunto de Estatística, assim como questões contextualizadas.

Nesse sentido, para minimizar essas dificuldades, os alunos devem melhorar suas habilidades referentes aos seguintes conteúdos: Média, Mediana e Moda, pois através desse desenvolvimento os discentes terão a capacidade de organizar dados, tabelar informações, assim como interpretar dados (Lopes, 2008; Votto; Schreiber; Porciúncula, 2017; Hollas; Bernardi, 2020).

Ainda com relação a estes resultados, Silva et al. (2016) afirmam que os estudantes apresentam uma grande dificuldade na interpretação das questões ou problemas, onde a mesma está atrelada a falta de leitura, e que é de suma importância que essas dificuldades sejam sanadas para que o estudante consiga contextualizar e entender um problema.

Após a realização da intervenção foi realizado o pós-teste, onde os resultados foram tabelados por questão, esses resultados estão expostos a seguir através de gráficos. A primeira questão está associada ao assunto de Análise de Gráficos e noções de Média Aritmética, como mostra a Figura 9. 
Figura 9 - Questão 1: Retirada da prova de Enem de 2018.

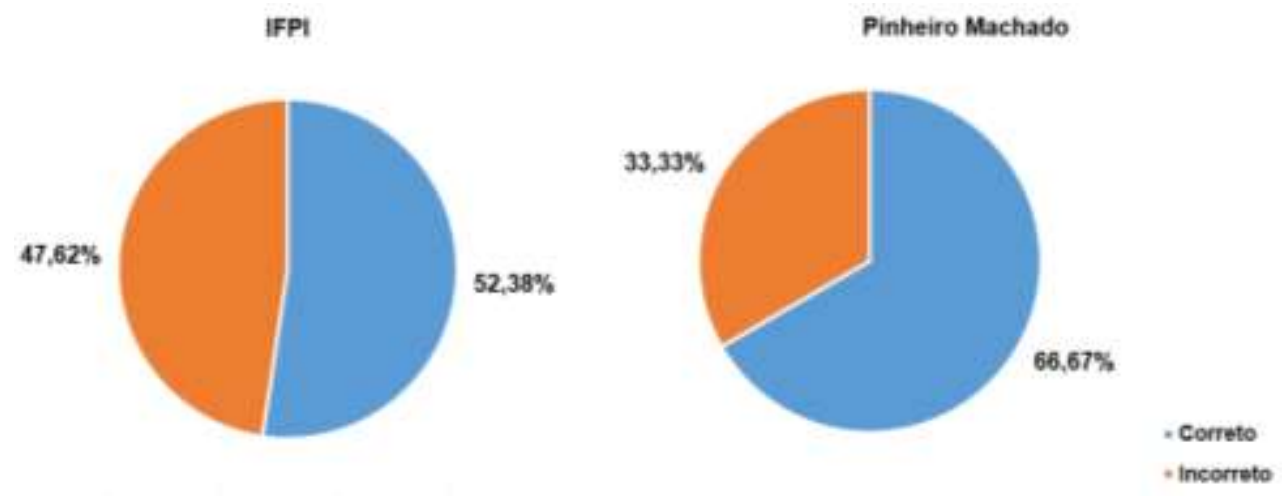

Fonte: Fonte: Autores (2021).

Após observar o resultado dessa questão, nota-se que as duas turmas conseguiram êxito na sua resolução, mais de fato apenas 52,38\% dos alunos do IFPI responderam corretamente. Já na turma do Pinheiro Machado, cerca de 66,67\% obtiveram êxito na resposta. Assim, pode-se observar que existem ainda algumas dificuldades a serem minimizadas, mas já houve uma evolução significativa em relação à questão do pré-teste que relacionava esse assunto de Média Aritmética.

Para a compreensão da questão 1, os alunos necessitavam realizar a interpretação do seu enunciado e a partir disso solucionar o problema da mesma. Desse modo, para responder questões contextualizadas os discentes devem ter o domínio de leitura e interpretação de texto, para o entendimento e resolução correta da mesma (Roedel, 2016; Pontes et al., 2018; Araujo Junior; Trindade; Oliveira, 2019). Deve-se ressaltar que a contextualização deve estar presente no processo de ensino e aprendizagem do aluno, tendo em vista que esse tipo de abordagem possibilita ao discente associar os conteúdos vistos teoricamente com o seu cotidiano (Rodrigues, 2013; Maffi et al., 2019; Marques; Couto; Lima, 2019; Pontes, 2019).

A segunda questão, também associada à Média Aritmética, abordava uma situação bem presente na vida de um estudante que é a média de aprovação relacionada a cinco notas. Para responder essa questão os alunos contaram com o auxílio de uma tabela, sendo que para as respostas os discentes contaram com 5 alternativas, em que os resultados de erros e acertos se encontram sumarizados na Figura 10.

Figura 10 - Questão 2: Retirada da prova do Enem 2017.
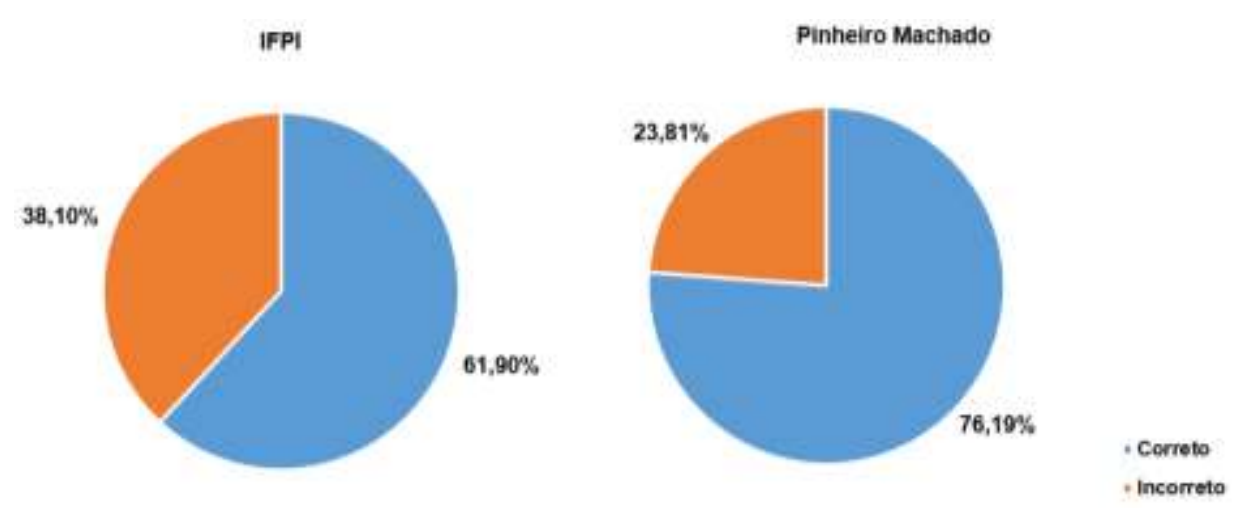

Fonte: Autores (2021). 
Com os resultados expostos acima, pode-se afirmar que os discentes das duas turmas tiveram um índice de acerto considerável, sendo que na turma do IFPI cerca de 61,90\% conseguiram responder à questão corretamente. Agora com relação a turma do Pinheiro Machado, cerca de 76,19\% obtiveram êxito na resposta.

$\mathrm{Na}$ terceira questão tem como assunto principal a Mediana associada a um gráfico, onde exige uma noção dos conceitos básicos desse assunto e domínio da operação de divisão (Figura 11).

Figura 11 - Questão 3: Retirada da prova do Enem de 2017.
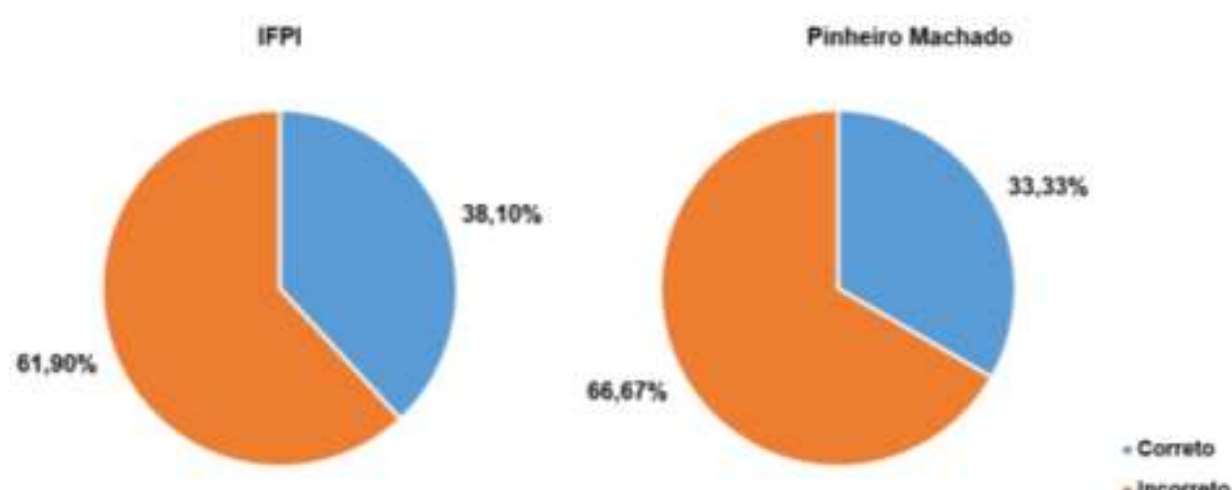

Fonte: Autores (2021).

Analisando o resultado dessa questão, percebe-se que as duas turmas tiveram o mesmo rendimento, na turma do IFPI apenas 38,10\% acertaram a questão, já os alunos do Pinheiro Machado, isto é, 33,33\% responderam corretamente. Assim, observa-se que os alunos ainda possuem certas dificuldades em relação à Mediana.

Com relação à quarta questão, novamente está relacionando conteúdos de Estatística com um quadro com várias informações para serem interpretadas sobre o assunto de Mediana, como mostra a figura 12.

Figura 12 - Questão 4: Retirada da prova do Enem de 2015.
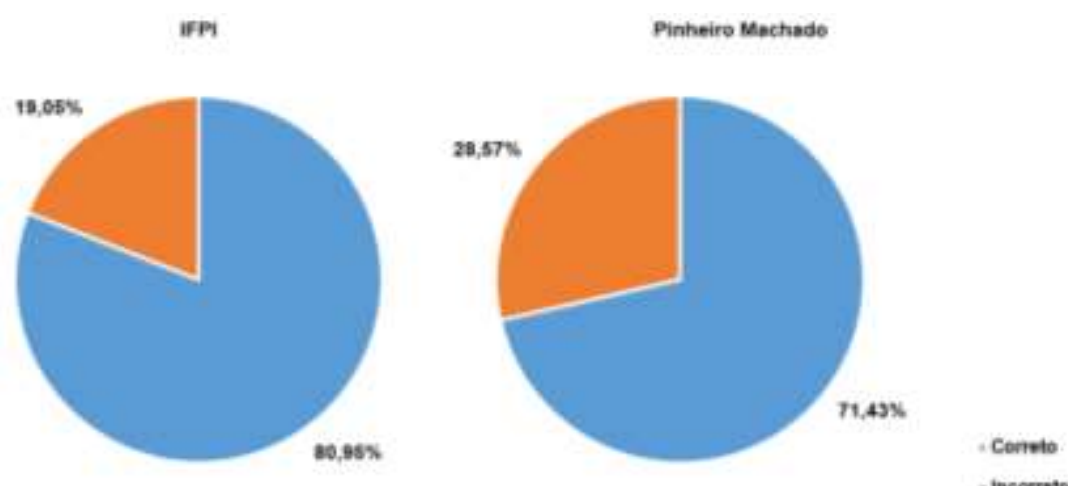

Fonte: Autores (2021).

Através dos dados acima, nota-se que novamente as duas turmas tiveram rendimentos parecidos, sendo que na turma do IFPI cerca de 80,95\% dos alunos obtiveram êxito na resposta da questão, já na turma do Pinheiro Machado 71,43\% dos alunos responderam corretamente.

Para a resolução correta da quinta questão o discente precisava do conhecimento de Média Aritmética relacionada a uma tabela, onde estão expostas informações sobre um concurso (Figura 13). 
Figura 13 - Questão 5: Retirada da prova do Enem de 2015.
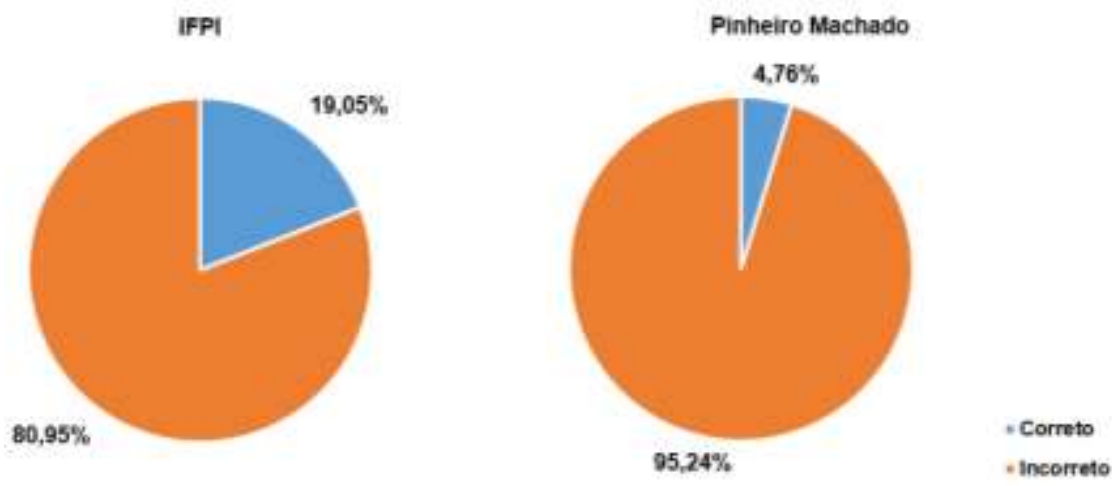

Fonte: Autores (2021).

Como mostra no gráfico, cerca de 80,95\% dos alunos do IFPI responderam a essa questão de forma incorreta. Agora ao observar o resultado do Pinheiro Machado nota-se que apenas 4,76\% tiveram êxito na resolução da questão. Com os resultados tabelados dessa questão, conclui-se que os discentes das duas turmas não tiveram êxito na resposta.

Durante a realização desse questionário, verificou-se a falta de conhecimento sobre Estatística, no qual interferiu na compreensão do enunciado e interpretação dos dados fornecidos na questão (Morais; Sturion; Reis, 2017; Silva, 2019; Costa; Moura, 2020). Ressalta-se que questões como esta, foram abordados durante a intervenção, assim como os conceitos sobre Média Aritmética, sendo que para uma resposta correta, o aluno necessitava ter conhecimentos sobre o assunto de Média Aritmética. Assim, a abordagem do conteúdo referente a Média Aritmética é de suma importância, pois a mesma é a base das demais medidas matemáticas trabalhadas em estatística (Cazorla, 2002; Cazorla; Santana; Utsumi, 2019; Luna; Carvalho, 2019).

Na sexta questão, para que o aluno tivesse um índice de acerto maior, o mesmo teria que analisar a tabela apresentada pela questão e o conteúdo de Estatística associado a essa tabela. Os erros e acertos para essa questão encontram-se ilustrados na Figura 14.

Figura 14 - Questão 6: Retirada da prova do Enem de 2014.
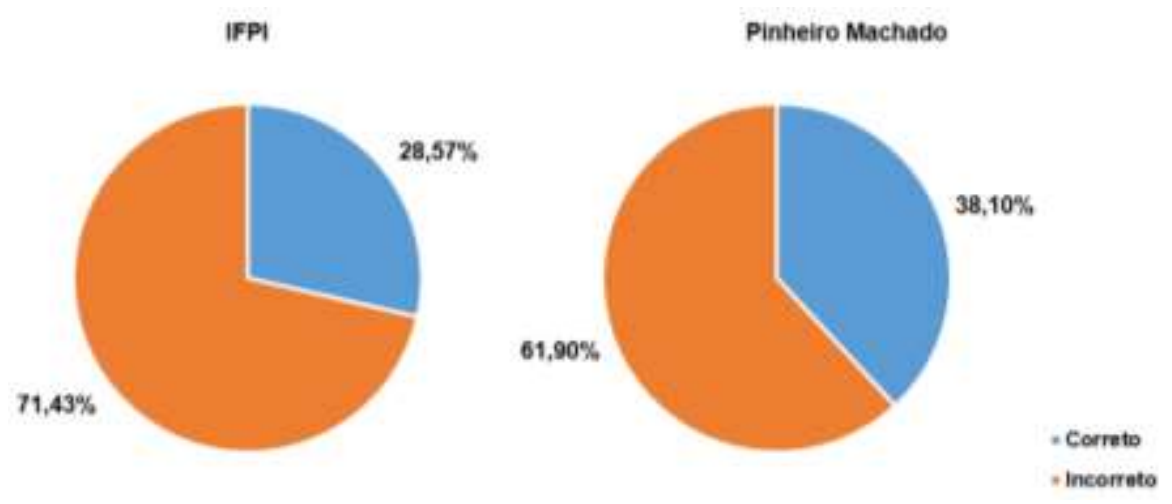

Fonte: Autores (2021).

Os resultados da Figura 14 mostram que os discentes têm ainda algumas dificuldades, visto que apenas $28,57 \%$ responderam corretamente, sendo que na turma do Pinheiro Machado o índice de acerto foi de 38,10\%, sendo está porcentagem maior do que a da turma do IFPI. 
A sétima questão estava relacionando o conteúdo de Média Aritmética tendo um gráfico de setores como auxílio, sendo que a interpretação do enunciado da questão era fundamental para sua resolução, a mesma falava sobre o valor mediano das diárias dos hotéis de uma determinada cidade. As respostas dos alunos para esta questão encontram-se na Figura 15.

Figura 15 - Questão 7: Retirada da prova do Enem de 2013.
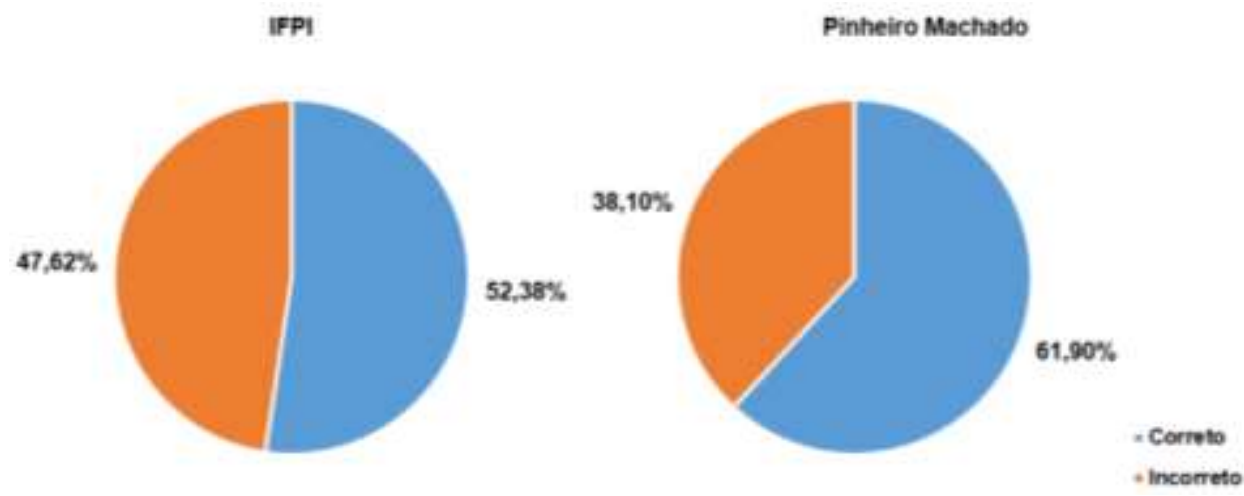

Fonte: Autores (2021).

Os resultados acima mostram que os alunos das duas turmas obtiveram êxito ao responderem à questão, mas o índice de acerto dos discentes do IFPI foi menor se compararmos com a turma do Pinheiro Machado, tendo cerca de 52,38\% e $61,90 \%$, respectivamente.

A oitava questão apresentava apenas como conteúdo principal a interpretação do gráfico, sendo o mesmo um gráfico de segmento ou gráfico de linha, mostrando a venda de um determinado remédio por mês durante um ano, onde a questão solicitava que o aluno interpretasse o gráfico e determinasse o mês que ocorreu a maior e a menor venda respectivamente. Os acertos e erros para essa questão encontram-se ilustrados na Figura 16.

Figura 16 - Questão 8: Retirada da prova do Enem de 2012
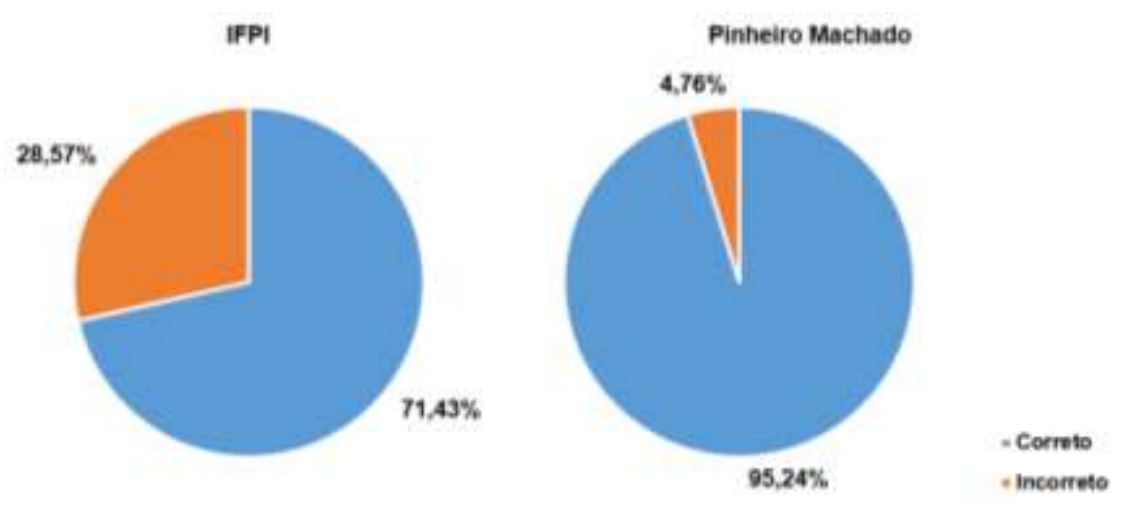

Fonte: Autores (2021).

Os resultados da figura 16 mostram que quase na sua totalidade os alunos das duas turmas obtiveram êxito na resposta, sendo que cerca de $71,43 \%$ dos alunos do IFPI responderam corretamente. Em relação ao rendimento da turma do Pinheiro Machado, pode-se perceber que 95,24\% dos alunos responderam corretamente. Tal resultado é relevante, tendo em vista a necessidade dos discentes possuírem conhecimentos no que se refere a interpretação e compreensão de gráficos.

Nota-se que de modo geral os discentes obtiveram um aproveitamento significativo com relação às questões com interpretações de gráficos como mostra o resultado da Figura 16, sendo um dos pontos mais abordados durante a intervenção. 
Assim a utilização de gráficos em questões facilita o entendimento, a interpretação, tornando-se uma ferramenta importante para o aluno, pois a matemática se utiliza de conteúdos abstratos (Ribeiro, 2007; Santos; Coqueiro, 2009; Diniz, 2016; Martins; Carvalho, 2018; Andrade et al., 2020).

\section{Considerações Finais}

Com o presente estudo foi possível realizar uma análise das provas do ENEM nos últimos sete anos, bem como aplicar questionários com os alunos das escolas IFPI Campus Cocal e Ensino Médio Deputado Pinheiro Mechado. Por meio disso, identificou-se o conteúdo mais abordado nas provas de ENEM, o que possibilitou visualizar as dificuldades que os discentes possuem relacionadas ao conteúdo.

Desse modo, com a análise do Banco de Dados do INEP, identificou-se que um dos principais conteúdos abordados pelo ENEM, nas questões de matemática, era o de Estatística. Além disso, com a aplicação dos questionários sobre as questões específicas do ENEM com as turmas das escolas Pinheiro Machado e IFPI, averigou-se que ambas as turmas apresentaram resultados semelhantes nas questões que foram aplicadas, apresentando taxas de erros e acertos semelhantes nos questionários.

A partir disso, ficou evidente que os alunos não detêm alguns conhecimentos essenciais para resolução de situações problemas envolvendo a estatística, fato este comprovado pelas respostas encontradas nos questionários. Ainda com relação aos questionários, constatou-se que os discentes possuem dificuldade no que se refere a questões contextualizadas, interpretação e compreensão de gráficos e tabelas.

Ainda, foi possível averiguar, por meio da intervenção realizada, as dificuldades que os discentes possuem em relação ao conteúdo de Estatística. Pôde-se ter ainda um contato com os alunos, tornando possível compreender o ambiente da sala de aula, onde ficou perceptível as diferenças dos ambientes de ambas as escolas. Desta forma, conclui-se que é evidente a necessidade de uma abordagem contextualizada ao trabalhar o conteúdo de Matemática de modo que os alunos possam relacionar os conteúdos vistos em sala de aula com o seu cotidiano e que estudos futuros, que tragam outras metodologias para trabalhar o conteúdo de Estatística, são válidos para serem acrescentados tanto na formação continuada do docente quanto na formação inicial do discente.

\section{Agradecimentos}

A Coordenação de Aperfeiçoamento de Pessoal de Nível Superior (CAPES) e a Fundação de Amparo à Pesquisa do Estado do Piauí (FAPEPI), pelas bolsas de estudo.

\section{Referências}

Albuquerque, C. S.; Cordeiro, N.J.N. \& Silva, M. N. (2013). A estatística nos documentos oficiais, no Enem e nos livros didáticos do ensino médio. Essentia, $15,123-141$.

Almeida, S. S. (2015). A importância do fies na garantia do direito ao ensino superior. https://editorarealize.com.br/artigo/visualizar/15200

Amaral, D. P. \& Oliveira, F. B. (2011). O Prouni e a conclusão do ensino superior: novas trajetórias pessoais e profissionais dos egressos. Ensaio: Avaliação e Políticas Públicas em Educação, 19 (73), 861-890.

Andrade, D. M., Batista, J. O., Santos, D. S. S. \& Mocrosky, L. F. (2020). A influência do Novo ENEM na relação de ensino e aprendizagem matemática: o caso da Escola Jorceli da Silva Sestari. Ensino e Multidisciplinaridade, 6 (1), 30-47.

Andrade, F. C., Schiller, C. V., Silva, D. A. F., Menezes, L. P. \& Silva, A. S. (2020). Aspectos da interpretação de gráficos de estudantes universitários em um ambiente virtual. Bolema: Boletim de Educação Matemática, 34 (67), 462-479.

Anjos, D. Z. \& Moretti, M. T. (2017). Ensino e Aprendizagem em Matemática para Estudantes Cegos: Pesquisas, Resultados e Perspectivas. JIEEM, 10 (1), $15-22$.

Arantes, H. \& Seabra, R. (2016). TME: Aplicativo M-Learning para o Estudo de Conceitos Matemáticos com Ênfase no ENEM. https://brie.org/pub/index.php/sbie/article/view/6675 
Araújo, F. C. (2021). Estatística na bncc: proposta de atividades para os anos finais do ensino fundamental. Brazilian Journal of Development, 7 (1),10441050 .

Araujo Junior, F. P. S., Trindade, A. K. B. \& Oliveira, L. J. N. (2019). Histórias em quadrinhos como ferramenta de contextualização de conceitos matemáticos. Ensino da Matemática em Debate, 6 (1), 34-45.

Brasil. (1996). Lei $n^{o}$ 9394, de 20 de dezembro de 1996. Estabelece as diretrizes e bases da educação nacional. http://portal.mec.gov.br/seesp/arquivos/pdf/lei9394_ldbn1.pdf

BRASIL. (1998). Portaria MEC No 438. Institui o Exame Nacional do Ensino Médio - ENEM. http://www.crmariocovas.sp.gov.br/pdf/diretrizes_p01780181_c.pdf

Brasil - Mistério da Educação (MEC). (2000). PCN + Ensino médio: orientações educacionais complementares aos Parâmetros Curriculares Nacionais Ciências da Natureza, Matemática e suas Tecnologia. http://portal.mec.gov.br/seb/arquivos/pdf/CienciasNatureza.pdf

Carvalho, M. C. (2017). Por uma "Intradisciplinaridade” em matemática: estabelecendo conexões entre conceitos de matemática a partir de questões contextualizadas do Enem. http://repositorio.utfpr.edu.br/jspui/handle/1/20329

Cazorla, I. M. (2002). A relação entre a habilidade viso-pictórica e o domínio de conceitos estatísticos na leitura de gráficos. http://repositorio.unicamp.br/bitstream/REPOSIP/250925/1/Cazorla_IreneMauricio_D.pdf

Cazorla, I. M., Santana, E. R. S. \& Utsumi, M. C. (2019). O campo conceitual da média aritmética: uma primeira aproximação conceitual. REVEMAT: Revista Eletrônica de matemática, 14, 1-21.

Costa, D. D. D. \& Ferreira, N. I. D. B. (2017). O PROUNI na educação superior brasileira: indicadores de acesso e permanência. Avaliação: Revista da Avaliação da Educação Superior (Campinas), 22 (1), 141-163.

Costa, M. D. \& Moura, A. R. L. (2020). Conhecimentos e dificuldades manifestados por alunos da engenharia civil em uma avaliação diagnóstica de estatística. REAMEC - Rede Amazônica de Educação em Ciências e Matemática, 8 (1), 112-124.

Costa, R. D. (2014). Uma abordagem da matemática financeira no ensino médio para explicitar as metodologias do fundo de financiamento estudantil - FIES http://repositorio.ufc.br/handle/riufc/8828

Diniz, L. N. (2016). Leitura, construção e interpretação de gráficos estatísticos em projetos de modelagem matemática com uso das Tecnologias de Informação e Comunicação. https://repositorium.sdum.uminho.pt/bitstream/1822/54635/1/Leandro\%20do\%20Nascimento\%20Diniz.pdf

Faria, L. M. \& Duque, T. O. (2021). Análise dos relatos apresentados no XII ENEM: a relação professor-aluno e as tendências para o ensino de matemática. ForScience, 9 (1), e00855.

Felicetti, V. L. \& Cabrera, A. F. (2017). Resultados da Educação Superior: o ProUni em Foco. Avaliação: Revista da Avaliação da Educação Superior (Campinas), 22 (3), 871-893.

Fidelis, A. K. \& Geglio, P. C. (2019). Interdisciplinaridade e contextualização: desafios de professores de ciências naturais em preparar os alunos para o enem. REnCiMa, 10 (6), 215-234.

Giordano, C. C., Araújo, J. R. A. \& Coutinho, C. Q. S. (2019). Educação Estatística E A Base Nacional Comum Curricular: O Incentivo Aos Projetos. REVEMAT, 14,1-20.

Hachem, D. W. \& Kalil, G. A. A. (2016). O direito fundamental social à educação e sua maximização por meio da função extrafiscal dos tributos: o exemplo do Programa Universidade para Todos (Prouni). A\&C-R. de Dir. Adm. Const., 16 (66), 153-177.

Hollas, J. \& Bernardi, L. T. M. S. (2020). O Exame Nacional do Ensino Médio (Enem) e as competências para uma Educação Estatística Crítica. Ensaio: Avaliação e Políticas Públicas em Educação, 28 (106), 110-134.

Leitão, F. M. P. $\quad$ S. (2011). Estatística $e$ realidade no cotidiano dos alunos. https://ppgmat.ufersa.edu.br/wpcontent/uploads/sites/58/2016/02/Disserta\%C3\%A7\%C3\%A3o-Francileide-Martins.pdf

Lima, E. G. S., Malange, F. C. V. \& Borges, L. F. (2018). Implicações do SiSU no processo de democratização do acesso à educação superior: o caso da Unemat. Acta Scientiarum. Education, 40 (1), e37656.

Lopes, C. E. (2008). O ensino da estatística e da probabilidade na educação básica e a formação dos professores. Cadernos CEDES., 28 (74), $57-73$.

Lopes, C. E. (2013). Educação estatística no curso de licenciatura em matemática. Bolema: Boletim de Educação Matemática, 27 (47), $901-915$.

Luna, L. C. \& Carvalho, J. I. F. (2019). “Oi, Quem está olhando minhas estatísticas?” - Uma discussão do desempenho de estudantes da Educação Básica sobre média aritmética. Amazônia - Revista de Educação em Ciências e Matemática, 15 (33), 151-166.

Maffi, C., Prediger, T. L., Rocha Filho, J. B. \& Ramos, M. G. (2019). A Contextualização na aprendizagem: percepções de docentes de ciências e matemática. Revista Conhecimento Online, 2 (11), 76-92.

Martins, M. N. P. \& Carvalho, C. F. (2018). O ensino de gráficos estatísticos nos anos iniciais. REnCiMa, 9 (2), $247-264$.

Marques, S., Couto, A. \& Lima, C. (2019). Contextualização de problemas de matemática: suporte para uma aprendizagem com significado. Sensos-e, 6 (2), 36-50.

Miranda, P. R. \& Azevedo, M. L. N. (2020). Fies e Prouni na expansão da educação superior brasileira: políticas de democratização do acesso e/ou de promoção do setor privado-mercantil?. Educação \& Formação, 5 (3), e1421. 
Moreira, G. E. (2015). A Educação matemática inclusiva no contexto da pátria educadora e do novo pne: reflexões no âmbito do gd7. Educ. Matem. Pesq., 17 (3), 508-519.

Morais, D. A. M., Sturion, L. \& Reis, M. C. (2017). Um estudo exploratório da educação básica sobre o ensino de estatística e o uso de tecnologias midiáticas. Ensino da Matemática em Debate, 4 (2), 61-86.

Nakayama, B. C. M. S. \& Silva, J. F. (2017). Formação matemática do professor polivalente: um estudo metanalítico. REAe - Revista de Estudos Aplicados em Educação, 2 (3), 3-16.

Oliveira, B. C., Santana, P. V. S., Altino Filho, H. V., Borges, L. H. F. \& Siqueira, M. L. G. (2020). O enem e as transformações na educação do país. http://pensaracademico.unifacig.edu.br/index.php/semiariocientifico/article/view/2240

Piton-Gonçalves, J. \& Almeida, A. M. (2018). Análise da dificuldade e da discriminação de itens de Matemática do ENEM. REMAT: Revista Eletrônica da Matemática, 4 (2), 38-53.

Pontes, E. A. S., Pontes, E. G. S., Silva, R. C. G. \& Silva, L. M. (2018). Abordagens ImprescindíveisnoEnsino Contextualizado de Matemática nas Séries Iniciais da Educação Básica. RACE - Revista de Administração do Cesmac, 1, 3-15.

Pontes, E. A. S. (2019). Os Quatro Pilares Educacionais no Processo de Ensino e Aprendizagem de Matemática. TEyET, 24, e02.

Pontes, J. \& Núñez, I. (2019). Questões de Estatística e Probabilidade nas provas do ENEM: uma aproximação a erros e dificuldades de aprendizagem. Revista Cerrados, 3 (7), 87-110.

Ribeiro, G. A. \& Mendes, A. A. (2016). A Dificuldade de Resolução das Questões de Matemático do Exame Nacional do Ensino Médio: Ineficiência Matemática Interpretativa?. https://www.google.com/url?sa=t\&rct=j\&q=\&esrc=s\&source=web\&cd=\&ved=2ahUKEwiLmvC_iNzwAhXyqpUCHZokCJIQFjAAegQIAxAD\&url=http\%3 A\%2F\%2Fpensaracademico.unifacig.edu.br\%2Findex.php\%2Fsemiariocientifico\%2Farticle\%2Fdownload\%2F127\%2F106\&usg=AOvVaw1PUXdNKWnzky oDrmplbSK5

Santos, A. A. (2021). Ensino de matemática nos anos iniciais: uma análise da base nacional comum curricular (bncc) na perspectiva contextualizada. http://200.17.114.109/bitstream/riufal/7567/1/Ensino\%20de\%20matem\%c3\%a1tica\%20nos\%20anos\%20iniciais\%20uma\%20an\%c3\%a1lise\%20da\%20base\% 20nacional $\% 20$ comum $\% 20$ curricular $\% 20 \% 28 \mathrm{BNCC} \% 29 \% 20$ na $\% 20$ perspectiva $\% 20$ contextualizada.pdf

Santos, G. I. \& Coqueiro, V. S. (2009). Vivendo a estatística na escola através de gráficos e tabelas. http://www.diaadiaeducacao.pr.gov.br/portals/pde/arquivos/1524-8.pdf

Santos, J. A., França, K. V. \& Santos, L. S. B. (2007). Dificuldades na Aprendizagem de Matemática. http://www.educadores.diaadia.pr.gov.br/arquivos/File/2010/artigos_teses/MATEMATICA/Monografia_Santos.pdf

Santos, J. P., Carneiro, R. S., Carneiro, R. S. \& Silva, K. F. (2020). Contextualizando o ensino de matemática com o uso do jogo de xadrez. revista uniaraguaia (Online), 15 (3), 54-66

Santos, V. D. F. L., Almeida, H. K. S. L., Carvalho, E. M., Souza, T. L. S., Lima, R. L. F. A. \& Lima Júnior, C. (2021). Ensino de matemática e Educação Ambiental: modelagem com energias renováveis no semiárido brasileiro. Revista Brasileira De Educação Ambiental (RevBEA), 16 (1), 148 -162.

Silva, D. B., Moreira, A. A., Silva, K. R., Delaia, M. M. \& Soares, N.N. (2018). Principais dificuldades enfrentadas no enem pelos alunos do terceiro ano do ensino médio de uma escola pública para aprendizagem de grandezas e medidas. http://editorarealize.com.br/editora/anais/enalic/2018/443-53624-30112018225145.pdf

Silva, M. F. \& Santos, G. O. (2021). Abordagem da estatística em livros didáticos de matemática do ensino médio do PNLD 2018: o letramento estatístico. Revista Eletrônica de Educação Matemática - REVEMAT, 16, 01-23.

Silva, M. V. (2014). As dificuldades de aprendizagem da Matemática e sua relação com a matofobia. http://dspace.bc.uepb.edu.br/jspui/bitstream/123456789/6666/1/PDF\%20-\%20Meiriane\%20Vieira\%20da\%20Silva.pdf

Silva, J. F., Curi, E. \& Schimiguel, J. (2017). Um Cenário sobre a Pesquisa em Educação Estatística no Boletim de Educação Matemática - BOLEMA, de 2006 até 2015. Bolema, 31 (58), 679-698.

Silva, L. I. B., Silva, I. S. V. C., Silva, L. O. P. \& Amorin, M. (2016). Contextualização Matemática: A dificuldade dos educandos na interpretação de problemas na educação básica. http://www.sbembrasil.org.br/enem2016/anais/pdf/8213_4295_ID.pdf

Silva, T. V. (2019). Resolução de problema em Estatística: um estudo sobre as principais dificuldades enfrentadas pelos estudantes da $3^{\circ}$ série do Ensino Médio. https://repositorio.ufpb.br/jspui/bitstream/123456789/17101/1/TVS04102019.pdf

Soares, D. J. M., Soares, T. E. A. \& Santos, W. (2021). Análise da qualidade psicométrica da prova de matemática do Exame Nacional do Ensino Médio brasileiro de 2018. Revista Actualidades Investigativas en Educación, 21 (1), 1-29.

Reis, A. Q. M. (2012). Exame Nacional do Ensino Médio (ENEM) como indutor da prática curricular de professores de matemática a partir da perspectiva de contextualização. https://bibliodigital.unijui.edu.br:8443/xmlui/bitstream/handle/123456789/1830/Ana\%20Queli\%20Mafalda\%20Reis.pdf?sequence=1\&isAllowed=y

Reis, A. Q. M. \& Nehring, C. M. (2017). A contextualização no ensino de matemática: concepções e práticas. Educação Matemática Pesquisa., 19 (2), 339364.

Roedel, T. (2016). A Importância da content/uploads/2016/04/gd1_tatiana_roedel.pdf 
Research, Society and Development, v. 10, n. 6, e51610616041, 2021

(CC BY 4.0) | ISSN 2525-3409 | DOI: http://dx.doi.org/10.33448/rsd-v10i6.16041

Ribeiro, J. O. (2007). Leitura e interpretação de gráficos e tabelas: um estudo exploratório com professores. https://sapientia.pucsp.br/bitstream/handle/11259/1/Jose\%20Odair\%20Ribeiro.pdf

Rodrigues, M. U. (2013). Análise das questões de matemática do novo enem (2009 á 2012): reflexões para professores de matemática. http://sbem.iuri0094.hospedagemdesites.ws/anais/XIENEM/pdf/1029_804_ID.pdf

Vasconcelos, D. H. F. (2017). O ensino superior: uma reflexão sobre o fundo de financiamento estudantil (fies) e a privatização desse setor. https://editorarealize.com.br/artigo/visualizar/37715

Vargas, H. M. (2019). O sisu na berlinda: presente e uma provocação para o futuro. Educação em Revista, 35, e215020.

Votto, T., Schreiber, K. P. \& Porciúncula, M. (2017). Educação estatística nos anos iniciais do ensino fundamental. Cad. Pesq., 24, 143-158. 